\title{
Corrigendum: Implications of COVID-19 Vaccine Hesitancy: Results of Online Bulletin Board Interviews
}

\author{
Jack M. Gorman ${ }^{1 *}$, Sara E. Gorman ${ }^{1}$, William Sandy ${ }^{2}$, Nellie Gregorian ${ }^{2}$ and \\ David A. Scales ${ }^{1,3}$ \\ ${ }^{1}$ Critica Inc., Bronx, NY, United States, ${ }^{2}$ Fluent LLC, New York City, NY, United States, ${ }^{3}$ Department of Medicine, Weil Cornell \\ Medical College, New York City, NY, United States
}

Keywords: COVID-19, vaccine, online, hesitancy, trust

\section{OPEN ACCESS}

Approved by:

Frontiers Editorial Office,

Frontiers Media SA, Switzerland

${ }^{*}$ Correspondence:

Jack M. Gorman

Jack@criticascience.org

Specialty section: This article was submitted to Public Health Education and

Promotion,

a section of the journal

Frontiers in Public Health

Received: 02 February 2022

Accepted: 10 February 2022

Published: 08 March 2022

Citation:

Gorman JM, Gorman SE, Sandy W Gregorian N and Scales DA (2022)

Corrigendum: Implications of COVID-19 Vaccine Hesitancy: Results

of Online Bulletin Board Interviews.

Front. Public Health 10:868438.

doi: 10.3389/fpubh.2022.868438

\section{A Corrigendum on}

Implications of COVID-19 Vaccine Hesitancy: Results of Online Bulletin Board Interviews by Gorman, J. M., Gorman, S. E., Sandy, W., Gregorian, N., and Scales, D. A. (2022). Front. Public Health 9:757283. doi: 10.3389/fpubh.2021.757283

In the original article, we neglected to include the funder the Cornell Center for Social Science, which provided support to change the focus groups to online bulletin boards after the onset of the COVID-19 pandemic.

In the published article, there was an error regarding the affiliations for Jack M. Gorman, Sara E. Gorman, William Sandy, Nellie Gregorian and David Scales. While the first four authors were incorrectly listed as affiliated with Weill Cornell, the last author should also have Critica as an affiliation.

The authors apologize for these errors and state that they do not change the scientific conclusions of the article in any way. The original article has been updated.

Publisher's Note: All claims expressed in this article are solely those of the authors and do not necessarily represent those of their affiliated organizations, or those of the publisher, the editors and the reviewers. Any product that may be evaluated in this article, or claim that may be made by its manufacturer, is not guaranteed or endorsed by the publisher.

Copyright $\odot 2022$ Gorman, Gorman, Sandy, Gregorian and Scales. This is an open-access article distributed under the terms of the Creative Commons Attribution License (CC BY). The use, distribution or reproduction in other forums is permitted, provided the original author(s) and the copyright owner(s) are credited and that the original publication in this journal is cited, in accordance with accepted academic practice. No use, distribution or reproduction is permitted which does not comply with these terms. 